\title{
Las instancias narrativas en El Lazarillo De Ciegos Caminantes: Alonso Carrió de la Vandera, alias Concolorcorvo*
}

\section{The Narrative Instances In El Lazarillo De Ciegos Caminantes: Alonso Carrió De La Vandera, Alias Concolorcorvo}

\section{Resumen}

En 1771 y 1772 Alonso Carrió de la Vandera (1715?-1783) realizó un extenso viaje para describir y evaluar el camino de postas entre Buenos Aires y Lima. Su polifacético recorrido quedó narrado en detalle en El lazarillo de ciegos caminantes, un texto que presenta una conciencia escrituraria y un desarrollo argumental inusual para su contexto. En el presente artículo nos ocuparemos en particular de la construcción de un autor apócrifo, Don Calixto Bustamante Carlos Inca, alias Concolorcorvo, para reflexionar teóricamente sobre el problema de la atribución de los discursos y del nombre propio, y la condición de existencia del sujeto que firma y del autor empírico, ya que afirmamos que Carrió de la Vandera se convierte a su vez en un ser de papel al ingresar en las ficciones que erige e interrelacionarse en el mismo nivel diegético con sus creaciones.

Palabras claves Siglo XVIII; relato de viaje; El lazarillo de ciegos caminantes; autor apócrifo.

* El presente artículo constituye la primera parte de un estudio de mayor amplitud realizado en el marco de mi tesis doctoral dirigida por las Dras. María Coira y Rosalía Baltar, en la cual estudié la utilización de estrategias de desdoblamiento del yo en un arco temporal amplio, desde la segunda mitad del siglo XVIII y hasta mediados del siglo XIX en los territorios americanos. Este texto, por lo tanto, está pensado en correlación con el análisis realizado sobre los periódicos del padre Francisco de Paula Castañeda (1776-1832). 


\begin{abstract}
In 1771 and 1772 Alonso Carrió de la Vandera (1715?-1783) made an extensive trip to describe and evaluate the path of posts between Buenos Aires and Lima. His multifaceted journey was narrated in detail in El lazarillo de ciegos caminantes, a text that presents a scriptural awareness and an unusual plot development for its context. In this article we will deal in particular with the construction of an apocryphal author, Don Calixto Bustamante Carlos Inca, alias Concolorcorvo, to reflect on the problem of the attribution of the speeches and the proper name, and the condition of existence of the subject who signs and of the empirical author, since we affirm that Carrió de la Vandera becomes a paper being by entering the fictions he erects and interrelating on the same diegetic level with his creations.
\end{abstract}

Keywords Century XVIII; travel account; El lazarillo de ciegos caminantes; apocryphal author.

\title{
Introducción
}

En 1771 Alonso Carrió de la Vandera (1715?-1783) inició un extenso viaje para describir y evaluar el camino de postas entre Buenos Aires y Lima. Nombrado Visitador de Correo por la Corona en el marco de las Reformas Borbónicas, ${ }^{1}$ su polifacético recorrido quedó narrado en detalle en El lazarillo de ciegos caminantes, un texto que sin duda constituye un clásico de las letras coloniales no solo por las informaciones que contiene, sino por presentar una conciencia escrituraria y un desarrollo argumental inusual para su contexto.

\footnotetext{
${ }^{1}$ Nacido en Girón (España) se trasladó a los veinte años a América, primero a México -donde vivió más de una década-y luego a Lima, donde se instaló definitivamente e hizo sus negocios y carrera. Regresó a la península para pedir premios por sus servicios a la corona y en 1771 obtuvo el cargo. Entre 1750 y 1757 fue corregidor de la provincia de Chilques y Masques, cercana al Cusco; también fue alcalde mayor de Minas y subdelegado de Bienes de Difuntos. Luego de reintegrarse a la vida de comerciante, se dedicó a los negocios en Lima, Cusco y Charcas, hasta que en 1762, con motivo de la guerra anglo-española se alistó en el Regimiento de caballería de Nobles, formado por el virrey Amat para defender las costas peruanas de posibles incursiones. Cuando en 1767 se decretó la expulsión de los jesuitas, se ofreció para repatriar a un grupo a España. Al año siguiente se trasladó a la Corte para solicitar su recompensa por sus servicios a la Corona; si bien le negaron sucesivos pedidos de corregimientos, le otorgaron en 1771 el cargo de visitador de la Superintendencia de Correos y Postas para la ruta de Buenos Aires a Lima con la doble misión de inspeccionar y reorganizar las postas radicadas entre esos dos puntos, y mejorar el sistema postal de correos (Carilla; Altuna; Prieto).
} 
Varios elementos confluyen para permitir esta afirmación: en primer lugar, la publicación autogestionada en Lima entre 1775 y 1776, ya que, si bien los relatos de viaje eran de gran interés para el público contemporáneo, ${ }^{2}$ en general aparecían en periódicos o volúmenes europeos. ${ }^{3}$ En segundo lugar, la conjunción de aspectos documentales y literarios, propia de todo relato de viaje (Carrizo Rueda, «Cuestiones teóricas»; «Estudios preliminar. Construcción y recepción de fragmentos del mundo»), se exacerban en este caso hasta niveles poco observados otros relatos contemporáneos; así, mientras mantiene ciertas características de libro de viaje ilustrado reformista -describe los centros urbanos más importantes (Montevideo, Buenos Aires, Cusco, Lima, etc.) y las costumbres; estudia los sistemas comerciales de las zonas y las posibilidades de explotación de sus recursos, propone reformas económicas y administrativas, etc.-, presenta una elaboración retórica notable: el uso de anécdotas jocosas, cuentos y chistes que distienden el relato (Forace, 2014), la estructura dialógica que enfrenta dos sujetos letrados coloniales con una pertenencia racial y social diferente (Zanetti, «La trama de las voces en El lazarillo de ciegos caminante de Alonso Carrió de la Vandera»; Zanetti, «La trama de la lectura y la escritura en El lazarillo de ciegos caminantes de Alonso Carrió de la Vandera»; Pupo-Walker), y la ficcionalización autoral, es decir, la atribución del texto a Don Calixto Bustamante Carlos Inca, alias Concolorcorvo, indígena que acompañó efectivamente a Carrió de la Vandera en

${ }^{2}$ Diana Marre ha observado que durante el siglo XVIII el relato de viaje se tornó uno de los géneros preferidos del público inglés; así, por ejemplo, las publicaciones periódicas más importantes mantenían una sección permanente entre sus páginas donde recogían, por entregas o completos, relatos o crónicas de viaje (Marre). Igual relevancia ha observado Inmaculada Urzainqui en la prensa ilustrada española, en la cual los editores informaron a sus lectores sobre los descubrimientos territoriales más recientes, las novedades del género y la multitud de métodos y planes para viajar "con utilidad", a la vez que publicaron numerosos relatos de viaje (Urzainqui). Elena Altuna también se refiere a la aparición de nuevos componentes en los gustos del público, el cual manifiesta un gran interés por los relatos de viajes a países "exóticos" (Altuna).

${ }^{3}$ Los datos de publicación -lugar, año, imprenta- son falseados por su autor en la portada, quien divulga su obra sin autorización, sin embargo, están fijados en la actualidad en la imprenta de los "Huérfanos" de Lima entre el año 1775 y 1776 (Altuna). 
su recorrido, pero solo viajó con él desde Córdoba hasta Potosí (diez meses en total) y no llegó a Lima en su compañía. ${ }^{4}$

La controversia entre los críticos respecto de los motivos que llevaron al Visitador a utilizar este recurso en un relato de viaje empírico y de corte ilustrado, analizada en oportunidades anteriores (Forace, 2013), ${ }^{5}$ constituye la base sobre la que se apoyan las reflexiones del presente artículo, ya que interesa recuperar ese trabajo que pensó la ficcionalización como un recurso intencional que incorporaba lo político y lo literario en función de una intención retórica (presentar a Carrió de la Vandera como figura con autoridad y legitimidad para emitir juicios sobre la realidad colonial), para, a partir de ello, problematizar las instancias narrativas del relato. Consideramos que la figura de Concolorcorvo, un personaje de papel que lejos está del sujeto empírico Bustamente y que se hace responsable de El lazarillo, habilita la consideración de los diversos niveles narrativos y ficcionales que pone en juego el texto, al igual que abre la reflexión hacia el problema de la atribución de los discursos y el nombre propio, y la condición de existencia del sujeto que firma y del autor empírico, ya que afirmamos que Carrió de la Vandera se convierte

${ }^{4}$ Este aspecto de la obra originó arduos debates entre los críticos de principios del siglo XX luego de su reimpresión, ya que hubo quienes confundieron la estrategia del autor ficticio con una realidad. No obstante, los contemporáneos no desconocían que la autoría era de Carrió de la Vandera; como afirma Marcel Bataillon: "Don Alonso recurrió a una superchería, capaz quizá de engañar lectores no avisados, pero no a las autoridades" (1960: 204). Elena Altuna ubica la "genealogía del error" en el momento en que la cultura criolla se empeñó en "nacionalizar" sus testimonios literarios y creyó más conveniente reivindicar un texto escrito por un indígena que por un español (181). A pesar de esto, la autoría de Carrió ha quedado demostrada en la década del '50 gracias a los trabajos de José Torres Revello, Federico Mojardín, José Real Díaz (Carilla), y, posteriormente, con los de Bataillon y Emilio Carilla.

${ }^{5}$ Las hipótesis de la crítica respecto de los motivos para apelar a la figura de Concolorcorvo son tan disímiles como los intereses y juicios que cada investigador ha volcado en la obra: algunos minimizan su valor artístico y eligen concentrarse únicamente en su carácter de testimonio de época (Bataillon; Pupo-Walker; Ocasio), mientras otros reconocen su valor literario y exploran su construcción retórica, sus fuentes literarias, sus licencias poéticas, sus anécdotas jocosas, etc., tomando en cuenta la relevancia que tuvo, en comparación con otras producciones del periodo, en el campo de las letras (Carilla; Borello; Lorente Medina; Altuna; Martínez Gramuglia). Otra línea afirma que la caracterización de Concorlorcorvo y el seudodiálogo que entabla con el visitador funciona como una forma de asumir la realidad del mestizaje (Bataillon) o de expresar la compleja red de posiciones de los sujetos respecto del discurso metropolitano (Zanetti, "La trama de la lectura y la escritura en El lazarillo de ciegos caminantes de Alonso Carrió de la Vandera"). 
a su vez en un ser de papel al ingresar en las ficciones que erige e interrelacionarse en el mismo nivel diegético con sus creaciones. ${ }^{6}$

\section{Seudónimos, apócrifos y heterónimos}

El juego literario con autores ficticios tiene conocidos antecedentes en la literatura; por ejemplo, el Siglo de Oro español nos ha dejado el ineludible Don Quijote de la Mancha de Miguel de Cervantes y las Rimas humanas y divinas del licenciado Tomé Burguillos de Lope Félix de Vega Carpio, ${ }^{7}$ en los cuales sus autores empíricos se presentaron como meros “editores" o "prologuistas” y, si bien jugaban con los límites de la ficción, nunca abandonaron un pacto de lectura ficcional. Diferente es el caso a considerar, ya que El lazarillo de ciegos caminantes apela a otro régimen de verdad según el cual es plausible presentar un viaje empírico de un sujeto real (Carrió de la Vandera) por medio de una voz apócrifa sin que pierdan veracidad las informaciones dadas o las posiciones expuestas.

De modo que, antes de avanzar sobre estos aspectos debemos delimitar, al menos someramente, los términos que suelen ponerse en juego al trabajar las diversas variedades de sujetos enunciativos, como "máscara", "apócrifo" y "heterónimo", ya que esta distinción se hace ahora necesaria en pos de una mejor comprensión de las modalidades particulares que se ensayan. En líneas generales,

${ }^{6}$ Gérad Genett identificó diferentes niveles narrativos: en el primer nivel, el extradiegético, correspondiente al acto literario (un narrador extradiegético que se dirige a un público real, aunque sea un personaje ficticio); un segundo nivel diegético o intradiegético, es decir. los acontecimientos contados en ese acto literario; y un tercer nivel metadiegético, los relatos en segundo grado contados por un personaje.

${ }^{7}$ Lope había utilizado con anterioridad seudónimos muy conocidos, como el de Belardo, su nombre pastoril, el padre Gabriel Padecopeo, Zaide de los romances moriscos, Lucindo de La Hermosa de Angélica, etc.; empero, Burguillos es el primero con el cual intenta poner en duda los límites entre real y ficticio. Por ejemplo, en el "Advertimiento al señor lector" dice: "se sabrá también que no es persona supuesta, como muchos presumen, pues tantos aquí le conocieron, y trataron, particularmente en los premios de las justas, aunque él se recatava de que le viesen, más por el desluzimiento de su vestido, que por los defectos de su persona; y asimismo en Salamanca, donde yo le conocí, y tuve por Condiscípulo, siendolo entrambos del Doctor Pichardo, el año que llevó la Cátedra del Doctor Vera" (s/folio, se respecta tipografía, las cursivas nos pertenecen). 
cada uno de estos términos apunta a una falta de correspondencia entre el nombre del autor empírico y quien firma el texto, aunque existen diferencias respecto de la forma en que llenan la referencia de esa firma, pues pueden ser desde meros nombres alternativos o artísticos hasta personalidades literarias completas y diferenciables del autor empírico.

El caso más usual de esta falta de correspondencia es el del seudónimo, nombre falso que usa el autor para ocultar el propio, muy habitual en el caso de obras artísticas, como el dramaturgo Jean-Baptiste Poquelin, que eligió firmar sus textos como Molière, o el novelista Marie-Henry Beyle, que hizo lo propio como Stendhal. En estos casos, sin embargo, los niveles de ficción no son puestos en cuestión; esos nombres no constituyen personajes o seres literarios sino simplemente un reemplazo nominativo que siempre tiene la misma referencia. ${ }^{8}$

El término máscara tiene una relación directa con el anterior, porque, en tanto ocultamiento del nombre (o del rostro, para recuperar su significado original), parecería cubrir el mismo tipo de manifestaciones. No obstante, la crítica especializada no suele usarlos como términos equivalentes y utiliza máscara para los casos en que "advierten algún tipo de relación entre las experiencias o sentimientos expuestos en la escritura y la persona del autor, principalmente si éste no los asume de forma explícita como propios sino que los asigna en cambio a algún otro (nominado o no)" (Swiderski 129); por lo tanto, cuando no puede establecerse con claridad la atribución del discurso y el reconocimiento entre nombre real y nombre ficticio se ve obstaculizado, pero se correlaciona la vida y la escritura de un autor, suele utilizarse el término máscara por sobre seudónimo.

En este sentido, la máscara funciona bajo una dinámica paradójica de ocultamiento y reconocimiento, porque en tanto nombre diferente y experiencias o sentimientos no admitidos como propios, busca impedir que el que la usa sea

${ }^{8}$ Respecto de este punto, Liliana Swiderski afirma que "El seudónimo genuino, aquel que se ignora el verdadero nombre de autor, intenta hacerlo irreconocible (sea por juego, sea por necesidad), pero también [...] procura investir al autor con el poder de una máscara. Tal es el caso en los seudónimos en los que opera un cambio de sexo, o de aquellos en que se agrega un plus aristocrático al nombre (Conde de Lautremont)" (Swiderski 129). 
identificado, pero, por el contrario, para que ese ocultamiento sea reconocido como tal, es necesario poder establecer la "similitud entre la figura presentada y el rostro del autor" (Swiderski 130). Este reconocimiento puede producirse por una falla en la construcción retórica de los textos, que dejan en evidencia el recurso, o porque el autor intencionalmente ha dejado indicios al respecto, estableciendo de este modo un juego de desciframiento para sus receptores.

Ahora bien, la forma en que trabaja la máscara hace que el término pierda la especificidad requerida para diferenciar diversas manifestaciones porque, bajo su amparo se cobijarían por igual, por ejemplo, Beyle/Sthendal, Cervantes/el traductor anónimo/Cide Hamete Benengeli y Lope de Vega/Licenciado Burguillos, aunque es evidente que no funcionan de la misma forma: en el primer caso, se reemplaza el nombre real con otro artístico, pero no se duda de la identificación entre uno y otro; en el segundo, se atribuye la obra al autor empírico en la firma de la tapa y en la dedicatoria, ${ }^{9}$ aunque dentro del nivel extradiegético un traductor/narrador ficticio afirme que ha copiado a Cide Hamete; el tercero, reduce en la portada al autor empírico a editor y otorga la responsabilidad del contenido de la obra (los poemas recopilados) al ente de papel Burguillos. ${ }^{10}$

Diferenciemos, entonces, además del seudónimo ya mencionado, otras formas de desdoblamiento autoral: el apócrifo, cuando se atribuye una obra a alguien que no la compuso, ya sea que se trate de un sujeto real o que solo se cree real (y sea ficticio), y el heterónimo, que supone la ficción de un personaje-autor de una obra distinta de la de su creador. ${ }^{11}$ El primero se distingue del pseudónimo

${ }^{9}$ Recordemos la portada del libro: "EL INGENIOSO/ HIDALGO DON QUI/XOTE DE LA MANCHA./ Compuesto por Miguel de Cervantes/ Saavedra./ DIRIGIDO AL DUQUE DE BEJAR". También la dedicatoria lleva al final la firma de Cervantes.

${ }^{10}$ La tapa dice: "RIMAS/ HUMANAS Y DIVINAS,/ DEL LICENCIADO TOMÉ BURGUILLOS, NO SACADAS DE BIBLIOTECA NINGUNA, (que en Castellano se llama Libreria) sino de papeles de amigos/ y borradores suyos./ AL EXCELENTÍSSIMO SEÑOR DUQUE DE/ Sessa, Gran Almirante de Nápoles./ POR FREY LOPE DE FÉLIX DE VEGA CARPIO/ del Áuito de San Juan".

${ }^{11}$ El creador del término fue Fernando Pessoa, quien adjudicó gran parte de su obra poética a personalidades literarias, como Alberto Caeiro, Ricardo Reis, Álvaro de Campos, entre otros. A ellos los llamó heterónimos para distinguirlos de la categoría de seudónimos, porque para él poseían vida propia, biografía autónoma de su creador y una obra que se correspondía con cada una de sus personalidades, mas no la suya. A pesar de que la noción se desprende de los 
en que el autor apócrifo no ha hecho realmente la obra que se le atribuye; asimismo juega con cierta ambigüedad en el reconocimiento por parte del lector, quien puede identificar el autor con el personaje que firma (leerlo como seudónimo, es decir, autor apócrifo=autor empírico) o puede rastrear ciertos indicios de él en opiniones volcadas en el texto o en ciertos pasajes pero sin establecer una equivalencia completa entre la identidad de ambos (es decir, autor empírico autor apócrifo). Como señala Liliana Swiderski, "El lector sabe que existe algún tipo de identificación entre el autor y sus apócrifos, pero la imprecisión existente le permite moverse con relativa libertad entre diferentes combinaciones" (115). En el caso de los heterónimos se trata de personalidades ficticias, diferentes a las del autor, en el sentido de que no puede ser reconocido en el estilo o en las afirmaciones, como sí ocurre con los apócrifos, y que poseen, en general, una construcción más elaborada (tienen, por ejemplo, una biografía y una historia). Sin embargo, el autor empírico las reconoce públicamente como sus creaciones y funciona como marco y garante para todas ellas. ${ }^{12}$

El uso de máscaras (como término abarcador) y seudónimos, apócrifos y heterónimos (distinguiendo los grados del desdoblamiento), constituye una expresión clara de la forma en que el autor piensa su propia figura. Por este motivo, nos concentraremos a continuación en las estrategias que usa Carrió de la Vandera para construir su autor de papel, Concolorcorvo, y la relación que establece con él en el nivel textual.

cuestionamientos posmodernos a la identidad y la unidad del sujeto, ha sido utilizada por la crítica para definir manifestaciones anteriores, como ocurre con la caracterización del Licenciado Burguillos de Lope de Vega como heterónimo.

${ }^{12}$ Los ejemplos paradigmáticos de ambos tipos son los apócrifos de Antonio Machado, cuyos pasajes podrían ser adjudicados de forma directa a él por la cercanía de opiniones (como las obras de Juan de Mairena), y los heterónimos de Fernando Pessoa. Existe una amplia bibliografía que analiza este aspecto, pero remitimos a Liliana Swiderski porque no solo se ocupa del estudio de sus obras de forma comparativa, sino que también delimita teóricamente la extensión de los términos. 


\section{Carrió de la Vandera, alias Concolorcorvo}

... me dijo el visitador: "Eh, bien, monsieur Concolorcorvo; supongamos que en las tertulias y estrados se critique su gran itinerario histórico, por lo que toca a esta parte, y que se falle que su trabajo fue perdido y que toda la obra no vale un comino. ¿Qué cuidado tendrá Vd. de esto, después de haber vendido a buen precio sus brochuras? Reniegue Vd. y dé al diablo la obra o composición de que no se hable mal. Ninguna ha salido hasta ahora al gusto de todos, y hay infinidad de sujetos que no siendo capaces de concertar un periodo de seis líneas en octavo, que ponen un defecto en las cláusulas del hombre más hábil. Todo esto es oro molido para el autor. Si Vd. logra sacar el costo de su impresión (que lo dudo mucho) aunque la Robada le haga mucha gracia por mi respeto y amistad antigua, siempre gana Vd. mucho difundiendo su nombre y apellido por los dilatados dominios de España, con más fundamento que Guzmán de Alfarache y Estebanillo González, que celebran tantos sabios e ignorantes, en distinto sentido".

El lazarillo de ciegos caminantes

Las diferentes formas de duplicación de la instancia narrativa que mencionamos encuentran una expresión completamente inusual en El lazarillo, no porque usar un nombre de autor falso haya constituido una novedad, sino porque esta estrategia no había sido ensayada con anterioridad en relatos de viaje no ficcionales. Solo encontramos ejemplos en narraciones imaginarias, como las de Robinson Crusoe de Defoe, pero en verdad no puede considerarse un antecedente de la experimentación discursiva que realiza el Visitador.

En tanto estrategia, la de Carrió de la Vandera se diferencia de los casos que nombramos porque no firma el texto y deja luego el relato en manos de un narrador/autor ficticio (caso Quijote) sino que, en línea con Lope de Vega, advierte al lector con una duplicación del sujeto enunciativo en la tapa y propone un contrato de lectura diferente: 
CATEDRAL Tomada: Revista de crítica literaria latinoamericana / Journal of Latin American Literary Criticism Las instancias narrativas en El Lazarillo De Ciegos Caminantes: Alonso Carrió de la Vandera, alias Concololcorvo

EL LAZARILLO DE CIEGOS CAMINANTES desde Buenos-Ayres, hasta Lima con sus Itineriarios las mas puntual observacion, con algunas noticias utiles á los Nuevos comerciantes que tratan en Mulas y otras Historicas. SACADO DE LAS MEMORIAS QUE hizo Don Alonso Carrió de la Vandera en este dilatado Viage, y Comision que tubo por la Corte para arreglo de Correos, y Estafetas, Situacion, y ajuste de Postas, desde Montevideo. POR DON CALIXTO BUSTAMANTE CARLOS Inca, alias CONCOLORCORVO Natural de Cuzco, que acompañó al referido Comisionado en dicho Viage, y escribió sus Extractos. CON LICENCIA. En Gijon, en la Imprenta de la Rovada. Año de $1773^{13}$ (Carrió de la Vandera). ${ }^{14}$

La inscripción en el paratexto principal del libro del nombre falso acerca el ejercicio al seudónimo; a pesar de ello, esta intuición es inmediatamente anulada porque conviven en el mismo espacio el visitador y el amanuense indígena, en un movimiento que nivela autor empírico y creación discursiva, y anuncia al lector otra forma de distribución de responsabilidades, tal como hacía, en apariencia, Lope. No obstante, si comparamos esta tapa con la de Rimas humanas y divinas, podemos identificar cuán diferente es la cadena de atribuciones entre una y otra: mientras en esta se adjudicaba el contenido del libro (los poemas) a un ser de papel (Burguillos), composiciones que eran recopiladas por el editor Lope de Vega (autor empírico), en el Lazarillo, por el contrario, las "noticias útiles" que se declaran como núcleo principal del libro son remitidas a Carrió de la Vandera (autor empírico) y copiadas por una creación imaginaria (Concolorcorvo). La diferencia entre los objetivos comunicativos de uno y otro obliga a desplazar ahora la reflexión hacia los niveles de ficción que cada uno elabora y que constituye, en nuestra

${ }^{13}$ Se respeta en esta cita la tipografía original de la primera portada del texto.

${ }^{14}$ La estrategia construida desde la tapa se pierde lamentablemente en algunas ediciones actuales del libro, las cuales, teniendo como marco los debates sobre la autoría que envolvieron al texto por años, parecen preferir dejar clara su atribución antes que mantener vivo en los paratextos el juego de duplicaciones; así ocurre, por ejemplo, en la edición de 1985 de Biblioteca Ayacucho. 
opinión, el aspecto más interesante de El lazarillo, porque en él, a pesar de duplicarse la instancia enunciativa por medio de la construcción de un ente de ficción, se quiere presentar informaciones verdaderas acerca de las colonias para que puedan ser aprovechadas por comerciantes, viajeros y funcionarios. ${ }^{15}$ ¿Qué pacto de lectura propone, entonces?

Pensemos, para comenzar, en el tipo discursivo que ensaya Carrió de la Vandera, es decir, el relato de viaje. La narración de un desplazamiento empírico y los datos allí presentados asientan su garantía de fidelidad de quien habla:

La función central de todo narrador de un relato de viaje, su deber implícito, es informar, y de acuerdo a los pactos que rigen el género, que tal información sea veraz, es decir, fiable. Tal fiabilidad se apoya en su carácter de testigo presencial, situación que se refuerza con el protagonismo de la mirada, que fija selecciones y jerarquías en el relato. (Colombi 31)

Con independencia de los prejuicios que circulaban en la época respecto de los "viajeros como embusteros", ${ }^{16}$ la información aportada en los relatos de viaje empírico era interpretada en general por el lector como "verídica, exacta y comprobable" (Uriarte 104). En consecuencia, la firma del nombre de autor era uno de los criterios de credibilidad de los textos porque la forma de establecer la diferencia con los viajes imaginarios era la existencia real del espacio recorrido, del viaje realizado y del viajero. Siguiendo el modelo del pacto de lectura autobiográfico, ${ }^{17}$ podríamos agregar que se necesitaba una coincidencia entre la

\footnotetext{
15 Véase Forace, "La configuración del espacio".

${ }^{16}$ Juan Pimentel ha estudiado cómo la credibilidad de los viajeros había sido muy cuestionada antes de que el advenimiento de ciencia moderna los identificara como testigos fidedignos; se entendía que en sus relatos desplegaban operaciones de transformación, tergiversación e invención destinadas a aumentar su reputación, que justificaba una fundada sospecha sobre su capacidad de producir conocimiento cierto. Otro trabajo de referencia ineludible sobre este tema es el clásico libro de Percy G. Adams, Travelers and Travel Liars. 1660-1800.

${ }^{17}$ Philippe Lejeune propuso la existencia de un "pacto de lectura autobiográfico" en el caso de la autobiografía, un "contrato" que establece una conexión entre lo textual y lo extratextual por
} 
firma en la tapa, la identidad de narrador y del protagonista. $\mathrm{Si}$, como ha señalado Pierre Bourdieu, "el nombre propio es el certificado visible de la identidad de su portador a través de los tiempos y de los espacios sociales” (Bourdieu 79), en el relato de viaje esa marca de referencialidad que constituye la firma de la tapa de un autor "real" funciona como orientación de la lectura y de la interpretación.

No ocurre así, sin embargo, en el texto de Carrió de la Vandera: se juega intencionalmente con la discrepancia entre las instancias enunciativas al enmascarar el nombre del visitador con un autor apócrifo, pero este ocultamiento del rostro del autor no se produce de forma completa, porque se lo convoca como fuente de los datos. ¿Se mantiene, pese a eso, la referencia última a un viajero "real", necesaria para las condiciones de credibilidad del género?

Recuperemos lo anterior: en el caso del Quijote, en el cual también se interviene la instancia narrativa, esta estrategia funciona en favor de una elaboración discursiva más compleja que no representa un riesgo para su función comunicativa, pues, en tanto texto de ficción, la verosimilitud se refuerza gracias a los diferentes narradores. No parece ocurrir lo mismo en el caso de El lazarillo, cuyas informaciones no se quieren verosímiles, sino verídicas; cabe preguntarse ¿supone la presentación de un personaje como responsable del acto enunciativo un

medio del cual el lector asume que las acciones de narrar, protagonizar, escribir y dar a publicidad provienen de una misma fuente -la identidad entre autor, narrador y personaje-. En sus trabajos más reciente amplió el pacto, comenzado a hablar de "pacto de verdad" o "pacto referencial" (el texto sería un correlato de la realidad y podría ser sometido a pruebas de verificación), por lo cual lo esencial que nos interesa recuperar es esa extensión del discurso de verdad que se ha prometido mantener. No intentamos recuperar aquí los debates teóricos acerca de la validez de la propuesta, pero es recomendable recordar que ni la primera definición de La autobiografía en Francia (1971) -con la fórmula reproducida hasta el cansancio de relato retrospectivo en prosa que una persona real hace de su propia existencia - ni la segunda que fundaba su distinción de la autobiografía y los relatos de ficción en el pacto autobiográfico (1973) son las reflexiones finales de este crítico sobre el asunto. El desconocimiento, a veces malintencionado, de los trabajos que siguieron a esos ejercicios iniciales, como "La autobiografía de los que no escribe" (1980) y "El pacto autobiográfico (bis)" (1982), no reconoce la transformación de sus postulados en el tiempo y las respuestas que ha dado a las numerosas objeciones. Por ejemplo, el problema del estatus ficticio del sujeto, existente solo como expresión de lenguaje, ampliamente señalado por teóricos como Paul De Man, no es desconocido por Lejeune, pero este elige mantener su idea de "pacto" porque reconoce que esa creencia es un hecho de la experiencia cultural contemporánea. Para una revisión de esta evolución en la reflexión, véase la recopilación de artículos de El pacto autobiográfico y otros textos. 
riesgo? Para responder a estos interrogantes, deberemos ahondar un poco en cómo funciona en el texto la dinámica entre el autor apócrifo y el visitador, y cuán consistente es su desarrollo.

Retomemos, para comenzar, una cita del prólogo del Lazarillo para concentrarnos ahora en cómo el autor apócrifo se inserta en una serie de mediaciones de escritura:

Yo soy indio neto, salvo las trampas de mi madre, de que no salgo por fiador. Dos primas mías coyas conservan la virginidad, a su pesar en un convento del Cuzco, en donde las mantiene el rey nuestro señor. Yo me hallo en ánimo de pretender la plaza de perrero de la catedral del Cuzco, para gozar de inmunidad eclesiástica, y para lo que me servirá de mucho mérito el haber escrito este itinerario, que, aunque en Dios y en conciencia lo formé con la ayuda de vecinos que a ratos ociosos me soplaban a la oreja, y cierto fraile de San Juan de Dios, que me encajó la introducción y los latines, tengo a lo menos mucha parte en haber parafraseado lo que me decía el visitador en pocas palabras. Imitando el estilo y éste, mezclé algunas jocosidades para entretenimiento de los caminantes, para quienes particularmente escribí. Me hago cargo de que lo sustancial de mi itinerario se podía reducir a cien hojas en octavo. En menos de la cuarta parte le extractó el visitador, como se puede ver de mi letra en el borrador, que para en mi poder, pero este género de relaciones sucintas no instruyen al público. (13, cursivas me pertenecen)

Lo que se había declarado de forma concisa en la portada del libro, es decir, la escritura de un relato basado en las memorias del visitador, se expande para incluir más detalles que sirven para relativizar la responsabilidad del discurso y debilitar la posición del amanuense: la instancia narrativa original sería el escrito del visitador (una cuarta parte de El lazarillo), texto parafraseado, intervenido y expandido por el amanuense indígena con anécdotas, chanzas y digresiones 
CATEDRAL Tomada: Revista de crítica literaria latinoamericana / Journal of Latin American Literary Criticism Las instancias narrativas en El Lazarillo De Ciegos Caminantes: Alonso Carrió de la Vandera, alias Concololcorvo

jocosas ${ }^{18}$ esta "escritura a dos manos" se transforma al multiplicar los colaboradores, cuyas intervenciones no pueden separarse claramente de la producción de Concolorcorvo porque, si bien los "latines" del fraile se identifican sin problema, queda en duda si el prólogo que estamos leyendo es de hecho la introducción mencionada $\mathrm{u}$ otra parte del libro, y mayor incertidumbre tenemos con los "vecinos" porque no se sabe con exactitud qué aportan al conjunto (¿son esos soplos en la oreja la impresionante colección de los chistes y cuentos sobre indios, negros y viajeros bisoños con la cual intenta deleitar al lector?).

La multiplicación de las fuentes del discurso divide responsabilidades -lo útil viene del visitador, lo "culto" del fraile y lo jocoso de Concolorcorvo- ${ }^{19}$ y expresa una cooperación entre sujetos de extracciones sociales disímiles bastante inverosímil en el contexto de época porque tanto el visitador y el fraile, como los "vecinos", eran necesariamente hombres blancos y libres que aparecen compartiendo autoría con un indígena. Esta contradicción evidente intenta ser enmendada de alguna forma al reforzar la verosimilitud de este extraordinario ejercicio de escritura por una vía doble: por un lado, ofreciendo la oportunidad de revisar el "borrador" donde se podrá comprobar la existencia de diferentes caligrafías; por el otro, la justificación de la escritura como medio para obtener un cargo, lo que sería coherente con las prácticas del momento.

Ahora bien, la ficción de esta escritura en colaboración no intenta "engañar" al lector, es decir, negar su carácter meramente discursivo. Al contrario, el juego de atribuciones presenta fisuras que no son disimuladas, sino que se explotan en favor de la comicidad o de los objetivos comunicativos. En la cita se observa, por ejemplo, la inestabilidad de la identidad del sujeto, quien se define como "indio neto", es decir, puro, e inmediatamente pone en duda este dato, "salvo las trampas

\footnotetext{
18 Para un análisis completo de estos aspectos, véase Forace "Nuevas condiciones de recepción".

19 Esto ha sido señalado ya por Rodolfo Borello, quien propone la existencia de una autoría compartida que permite a Carrió dividir responsabilidades: lo útil -distancia entre postas, caminos, opiniones sobre la conquista, etc.- pertenece a Carrió, lo entretenido -que podía restarle seriedad al texto y abrir el espacio a críticas- a Concolorcorvo.
} 
de mi madre", lo cual contradice de forma directa lo que había declarado en las primeras páginas, cuando se llamó a sí mismo "cholo" (5). ${ }^{20}$

El recelo mostrado aquí ante la conducta materna y ciertas declaraciones previas -como "aunque descendiente de sangre real, por línea tan recta como la del arco iris" (5)-, construyen una genealogía incierta y, principalmente, indigna, parodiando así, por un lado, cierta usanza escrituraria típica del momento que apelaba al pasado ilustre para darle más autoridad al sujeto enunciador, y, por el otro, al discurso de la dirigencia indígena que invocaba constantemente a lazos ancestrales con la nobleza incaica. En este sentido debe interpretarse también la justificación que da el amanuense para la escritura y publicación de su libro: frente a la mayoría de los cronistas de indias y funcionarios españoles que recorrieron América y dieron a la luz sus textos como forma de divulgación de los servicios prestados a la Corona y obtención de cargos y favores, Concolorcorvo escribe porque pretende una "plaza de perrero de la catedral del Cuzco", es decir, convertirse en uno de los que echaban los perros fuera de la Iglesia.

La indefinición y contradicción en la configuración del autor apócrifo se acentúan a lo largo del libro, aspecto en el que no nos detendremos por haberlo analizado anteriormente (Forace, "La construcción"), solo diremos que, las diversas descripciones físicas de Concolorcorvo, que dotan al ser de papel de un cuerpo y que deberían darle mayor densidad a su existencia funcionan, al igual que la inscripción familiar dudosa, como un mecanismo que declara su carácter ficcional porque sugieren raíces afroamericanas encubiertas.

La figuración de este autor apócrifo no persigue, por lo tanto, una construcción verosímil, pues juega continuamente con la inestabilidad de su identidad y siembra contradicciones en su formación y habilidad para producir un efecto humorístico y despejar dudas respecto de la ficcionalización de la instancia enunciativa. Debemos recuperar, entonces, el interrogante inicial por el objetivo de

20 Este aspecto había sido señalado ya por Elena Altuna, quien indicó que el "proceso de autocaracterización" conllevaba la creación de un sujeto inestable (197). 
esta duplicación porque es evidente que no tiene como finalidad “ocultar" el nombre del autor empírico. ${ }^{21}$

La clave se encuentra, en nuestra opinión, en la dinámica que se establece en el nivel narrativo entre el amanuense indígena y el visitador porque, más que parafrasear las susodichas memorias, Concolorcorvo se convierte en un narrador testigo de un relato en el cual Carrió de la Vandera es el protagonista.

Esta estrategia le otorga mayor libertad para llevar a cabo diversas operaciones retóricas: primero, la referida distribución de responsabilidades que habilita la inclusión de los chistes y anécdotas en voz del indígena, sin perder la seriedad de quien será el garante de la información útil; segundo, la reproducción de los diálogos entre ellos, lo que dinamiza la exposición argumentativa al usar a Concolorcovo como interlocutor que interroga al visitador y le permite enunciar sus opiniones acerca de la Conquista y el sistema colonial; tercero, construir una figuración elogiosa de sí mismo que no parezca tan presuntuosa al presentarla mediada por el indígena; y, por último, la inclusión de pasajes metatextuales, que exhiben cierto control sobre la escritura por parte del funcionario. Detengamos ahora en el punto final, ya que hemos abordado en otros artículos anteriores.

Aparte de la explicación de la mencionada cadena de atribuciones, El lazarillo presenta ciertos pasajes donde sus "autores" reflexionan acerca de su construcción y límites: "Iba a proseguir con mi prólogo a tiempo que al visitador se le antojó leerle, quien me dijo que [...] si se alargaba más se diría de él: Que el arquitecto es falto de juicio/ cuando el portal es mayor que el edificio" (14, cursiva

${ }^{21}$ Una parte importante de la crítica ha explicado esta construcción de un autor apócrifo por los problemas políticos que tuvo el visitador con el Administrador de Correos del Virreinato, José Antonio de Pando, los cuales habrían justificado ocultar su nombre para evitar posibles represalias por su contenido (Bataillon; Pupo-Walker, por ejemplo). Carrió de la Vandera fue designado visitador de la Superintendencia de Correos y Postas para la ruta Buenos Aires-Lima en 1771; antes de terminar su viaje en 1773 ya se habían originado conflictos con Pando por ciertas decisiones tomadas por el visitador. Incluso, luego de la publicación en 1777 de un "Manifiesto", esta vez sí firmado por Carrió, el enfrentamiento adquirió mayor gravedad porque Pando le inició un juicio en su contra y, como resultado, el visitador obtuvo la jubilación obligatoria en 1778. Esta interpretación, sin embargo, es desmentida o relativizada por estudiosos como Emilio Carilla porque no hay en realidad opiniones tan "peligrosas" que le impidieran a la obra circular, aunque reconocen que Concolorcorvo le sirvió como recurso para atacar a sus enemigos y a la vez diluir las responsabilidades. 
del original). La narración del viaje se detiene y se presentan estas escenas de corrección del manuscrito de El lazarillo, en las cuales el funcionario exhibe un saber letrado, "un saber decir", en palabras de Susana Zanetti ("La trama de las voces en El lazarillo de ciegos caminante de Alonso Carrió de la Vandera” 256). En este sentido, los consejos que le da a Concolorcorvo sobre no reseñar temas muy conocidos por los numerosos libros previos que los refieren (como la descripción de la zona peruana, que recomienda limitar) o acortar ciertas anécdotas y no desviarse del eje central de la narración da una imagen nueva sobre el visitador como autor, porque esas enmiendas y señalamientos aportan una forma de concebir la escritura como algo más que el registro de un diario de viaje: exige borradores y correcciones sucesivas.

En estas escenas, además, el tiempo se duplica y, sobre la línea de la narración del viaje de Buenos Aires a Lima, se proyecta otra posterior que coincidiría con el presente de la escritura, lo cual concordaría con la declaración del prólogo acerca de parafrasear las memorias del visitador: hay un tiempo del viaje, en el cual el funcionario escribe su texto, y uno posterior correspondiente a la reescritura de Concolorcorvo. Sin embargo, este orden cronológico no se mantiene estable durante todo el relato:

Después de haber descansado dos días en Potosí, pidió el visitador ver este diario, que cotejó con sus memorias y le halló puntual en las postas y leguas; y aunque le pareció difuso el tratado de las mulas, permitió que corriese así [...]. Quise omitir las coplas de los gauderios pero no lo permitió, porque sería privar al público del conocimiento e idea del carácter de los gauderios... (108)

Aquí, por el contrario, se presenta la simultaneidad entre el viaje y la escritura del indígena, línea que correspondería con la instancia de corrección, y que constituye otra forma de inconsistencia en la construcción del personaje Concolorcorvo. Asimismo, exhibe el criterio de inclusión de contenidos para el 
Lazarillo: lo que será interesante para el público tiene prioridad y se salva de la censura del visitador.

Ahora bien, el comentario respecto del tratado de las mulas, como descripción algo "difusa", muestra nuevamente la inestabilidad de los planos, pero esta vez, narrativos, pues unas páginas antes, en la susodicha explicación del comercio de mulas, se había dicho:

Aquí iba dar fin al asunto de las mulas, pero mi íntimo amigo don Francisco Gómez de Santibáñez, tratante años ha en este género, me dijo que sería conveniente me extendiese más [...]. Me pereció muy bien una advertencia que, cuando no sea muy útil, no puede desagradar al público general. [...] No me pareció del caso borrar lo escrito o posponerlo, y así sigo el asunto por modo retrógrado, o imitando los poemas épicos. (64)

¿Quién habla en este fragmento? Claramente, el visitador, quién otro podría llamar "íntimo amigo" a un tratante de mulas que además tiene la posición social necesaria para ser llamado "don". La duplicación de las instancias narrativas parece quebrarse aquí para dejar en evidencia la ficción y mostrar sin dudas la atribución verdadera de todo el discurso. Puede tratarse, como han querido ver algunos críticos, de una falla en el texto (Pupo-Walker), o, por el contrario, de una manera de expresar que el juego de voces era concebido exactamente como eso, un juego, el cual no pretendía "engañar" a nadie y, por lo tanto, no requería una construcción perfecta.

Retomemos nuevamente nuestro interrogante acerca de la construcción de un autor/narrador apócrifo. ¿Se mantiene, pese a eso, la referencia última a un viajero "real", necesaria para las condiciones de credibilidad del género relato de viaje empírico? Creemos que sí porque la conformación de una autoría no está dada por la unión de un nombre a un texto (vínculo que estaría presente en los seudónimos, heterónimos, etc.), sino por el reconocimiento social de la relación existente entre un cuerpo, un nombre y una obra (Swiderski). En efecto, los 
contemporáneos de Carrió de la Vandera nunca dudaron en atribuir el libro a su persona (a su cuerpo). Queda intervenido, entonces, el nivel del narrador ficticio, como ocurre en el caso del Quijote; al reconocer a Concolorcorvo como una construcción discursiva, incapaz de presentarse como origen del relato, reconstruir el vínculo entre autor empírico y escritura se convierte en algo inevitable. Se trata de una estrategia que no pretende ocultar el autor empírico, tal como lo demuestra la inestabilidad de la elaboración del personaje y la alteración en el nivel narrativo y en los planos viaje/escritura/corrección.

\section{Conciencia autoral}

La duplicación del autor y la creación de máscaras que, en su movimiento paradójico de ocultamiento y reconocimiento, intervienen en la instancia de atribución de los discursos es el asunto que nos interesó desarrollar en el presente artículo. La utilización de estrategias de desdoblamiento del yo en la segunda mitad del siglo XVIII constituye un aspecto de gran interés porque da cuenta de una preocupación por la figura autoral en textos orientados hacia lo factual y pensados para intervenir en los debates de su época.

Podríamos terminar nuestras reflexiones con la pregunta que se hizo Michel Foucault años atrás, “¿qué importa quién habla?”, o reformulándola en función de nuestro objeto, ¿es necesaria la marca del nombre propio en los textos del periodo que hemos elegido? En principio, El lazarillo lleva la marca de un nombre propio al cual suscribe sus páginas, una firma en la tapa que la convierte en un nombre de autor, es decir, en una indicación -como "un gesto, un dedo señalando a alguien" (Foucault 17)-y una descripción. Sin embargo, como sugiere Foucault, ese nombre de autor no funciona igual que un nombre propio, pues no necesariamente "señala" a un sujeto empírico.

Por eso la coincidencia de la firma en la tapa, del narrador y del protagonista de los hechos era un aspecto importante al considerar El Lazarillo de ciegos 
caminantes porque el autor apócrifo de Carrió de la Vandera transgrede las convenciones del relato de viaje empírico al intervenir esas instancias, acercando su relato al espacio de la ficción. La relevancia del nombre propio era incuestionable porque la atribución del discurso tenía efectos en el pacto de lectura que se ponía en juego.

Considero que retomar estas cuestiones permite observar cómo ese sujeto entendió las relaciones entre nombre propio, firma y autoría, en especial al ponerlas en correlación con las convenciones genéricas del tipo discursivo en los cual inserta su producción y los límites de la experimentación enunciativa en un momento determinado. En el caso de Carrió de la Vandera se trata de una estrategia completamente insólita no solo en el contexto de producción de los relatos de viaje, sino en la escritura del visitador. Recordemos que su segunda obra, Reforma del Perú, ${ }^{22}$ la cual también buscaba dar informaciones útiles y proponer un plan para los territorios americanos lleva, a diferencia de El lazarillo, la rúbrica de su autor y no intenta ningún tipo de elaboración ficcional.

Lo fundamental, entonces, es que el autor empírico no es borrado, ocultado o siquiera disimulado en el plano textual; por el contrario, Carrió de la Vandera se convierte una presencia ineludible inextricablemente enlazada con la ficción construida porque se vuelve a sí mismo en un ser de papel: la inscripción del visitador en secuencias narrativas enunciadas por Concolorcorvo lo transforman en personaje dentro de su propio universo ficcional. De esta forma, en vez de alejar la atención sobre él, su nombre es convocado una y otra vez como garantía o fuente última de los discursos y reorienta necesariamente la mirada hacia el autor empírico.

\footnotetext{
${ }^{22}$ El segundo impreso de Carrió de la Vandera que ha llegado a nosotros, Reforma del Perú o Plan para una Reforma Económica del Perú (1782) según las ediciones, profundiza el plan de reordenamiento y racionalización de los recursos de la colonia ya presentados en El lazarillo. En ese texto, el visitador propuso una provincia imaginaria ubicada en la zona de Cusco, donde implementar su proyecto de redistribución de habitantes, eliminación de cargos de Gobernadores y reemplazo por Intendentes que llevarán adelante el proyecto reformista borbón, erradicación de restos de la cultura y organización indígena -considera que la pervivencia de los caciques ha perjudicado históricamente los avances sobre el territorio-, entre muchas otras.
} 
Es evidente, por tanto, que debió reflexionar en particular sobre su importancia e interrogarse acerca del nivel de manipulación aceptable antes de emprender esta experimentación sobre esta instancia enunciativa. La creación de apócrifos, más que un procedimiento estético o un cuestionamiento acerca de la unidad del sujeto cartesiano (tendencia que será predominante en el siglo XX en el uso de estos recursos), se presenta como un juego retórico sobre la figura autoral y la atribución de los discursos que demuestra una conciencia clara sobre su propio rol.

\section{Bibliografía}

Adams, Percy G. Travelers and Travel Liars. 1660-1800. Berkeley: University of California Press, 1962.

Altuna, Elena. El discurso colonialista de los caminantes, (Siglos XVII-XVIII). Centro de Estudios Literarios Antonio Cornejo Polar (CELACP), Latinoamericana Editores, 2002.

Bataillon, Marcel. "Introducción a Concolorcorvo y su itinerario de Buenos Aires a Lima", Cuadernos Americanos CXI (1960): 197-216.

Borello, Rodolfo. “Alonso Carrió de la Vandera”. En Iñigo Madrigal, Luís (coord.), Historia y Crítica de la Literatura Hispanoamericana, 1. Barcelona: Cátedra, 1982. 151-157.

Bourdieu, Pierre., "La ilusión biográfica". Razones prácticas, sobre la teoría de la acción. Barcelona: Anagrama, 1997. 74-83.

Carilla, Emilio. El libro de los misterios, El lazarillo de ciegos caminantes. Madrid: Editorial Gredos, 1976.

Carrió de la Vandera, Alonso. El lazarillo de ciegos caminantes. Barcelona: Biblioteca Ayacucho, 1985.

Carrizo Rueda, Sofía. "Cuestiones teóricas". Poética del relato de viajes. Kassel: Edition Reichenberger, 1997. 1-34.

. "Estudios preliminar, Construcción y recepción de fragmentos del mundo". Escrituras del viaje, construcción y recepción de "fragmentos de mundo". Buenos Aires: Editorial Biblos, 2008. 9-34.

Colombi, Beatriz. "El viaje y su relato". Latinoamérica. Revista de Estudios Latinoamericanos, 43 (2006): 11-35.

Forace, Virginia P. "La construcción de la reputación autoral en El lazarillo de ciegos caminantes de Alonso Carrió de la Vandera", CELEHIS, Revista del Centro de Letras Hispanoamericanas, 1 (26), 2013: 167-182. 
Forace, Virginia P. "Nuevas condiciones de recepción en el siglo XVIII, aspectos jocosos en El lazarillo de ciegos caminantes, de Alonso Carrió de la Vandera", Estudios de Teoría Literaria - Revista digital, artes, letras y humanidades, 3 (5), 2014: 47-60.

Forace, Virginia P. "La configuración del espacio natural y el espacio urbano en El lazarillo de ciegos caminantes, de Alonso Carrió de la Vandera”, Cuadernos del Sur. Letras, 43, 2016: 89-106.

Foucault, Michel. “¿Qué es un autor?”. Obras esenciales. Entre Filosofia y Literatura. Buenos Aires: Paidós, 1999. 329-360.

Genette, Gérard. Figuras III. Madrid: Lumen, 1989.

Lejeune, Philippe. El pacto autobiográfico y otros estudios. Madrid: MegazulEndymion.

Lope de Vega y Carpio, Félix. Rimas humanas y divinas, del licenciado Tomé Burguillos. Madrid: Imprenta Real, 1674.

Lorente Medina, Antonio. "Introducción". Carrió de la Vandera, Alonso, El lazarillo de ciegos caminantes. Barcelona: Biblioteca Ayachucho, IXXXXV, 1985.

Marre, Diana. "Los "lazarillos" de la historia, relatos de viajeros, migración de estereotipos y construcción de identidades nacionales en el Río de la Plata decimonónico". Cicerchia, Ricardo (coord.), Identidades, género y ciudadanía, procesos históricos y cambio social en contextos multiculturales en América Latina. Quito: Abya Yala, 2005. 295-320.

Martínez Gramuglia, Pablo. "Un viajero colonial, escritura e historia en El lazarillo de ciegos caminantes". Bulletin of Hispanic Studies, 84/6 (2007): 821-834. doi,10.3828/bhs.84.6.8.

Ocasio, Rafael. "El Lazarillo de ciegos caminantes, una visión de la organización social en el mundo virreinal". Foster, David William y Altamiranda, Daniel (eds.), Writers of the Spanish Colonial Period, Spanish American literature 2. New York, 1997. 170-183.

Pimentel, Juan. Testigos del mundo, ciencia, literatura y viajes en la ilustración. Madrid: Marcial Pons Historia, 2003.

Prieto, Martín. Breve Historia de la literatura argentina. Buenos Aires: Taurus, 2006.

Pupo-Walker, Enrique. "Notas para una caracterización formal de El lazarillo de ciegos caminantes". Anales de Literatura Hispanoamericana, 9 (1980): 187-209.

Rodrigo, Enrique. "Un viaje algo circunstanciado: el destinatario de El lazarillo de ciegos caminantes". Villegas, Juan (ed.), Actas de XI Congreso de la Asociación Internacional de Hispanistas, 4. Asociación Internacional de Hispanistas, 1992. 21-27.

Swiderski, Liliana Noemí. Antonio Machado Fernando Pessoa, El gesto ambiguo (Sobre apócrifos y heterónimos). Mar del Plata: Editorial MartinEUDEM, 2006. 
Uriarte, Cristina G, de. “(D)escribir el viaje”. Literatura de viajes y Canarias, Tenerife en los relatos de viajeros franceses del siglo XVIII. Madrid: Editorial CSIC, 2006: 81-139.

Urzainqui, Inmaculada. "Un nuevo instrumento cultural, la prensa periódica". Álvarez Barrientos, Joaquín et al. (ed.), La República de las Letras en la España del siglo XVIII. Madrid: CSIC, 1995.126-216.

Zanetti, Susana. "La trama de las voces en El lazarillo de ciegos caminante de Alonso Carrió de la Vandera". Perilli, Carmen (ed.), Las colonias del Nuevo Mundo, discursos imperiales. San Miguel de Tucumán: Instituto Interdisciplinario de Estudios Latinoamericanos, Universidad Nacional de Tucumán, 1999. 255-265.

. "La trama de la lectura y la escritura en El lazarillo de ciegos caminantes de Alonso Carrió de la Vandera". La dorada garra de la lectura, lectoras y lectores de novela en América Latina. Rosario: Beatriz Viterbo Editora, 2010. 19-59. 